\title{
30 Years of Microsurfacing: A Review
}

\author{
Ben Broughton, Soon-Jae Lee, and Yoo-Jae Kim \\ Department of Engineering Technology, Texas State University, San Marcos, TX 78666, USA
}

Correspondence should be addressed to Soon-Jae Lee, soonjae93@gmail.com

Received 2 February 2012; Accepted 26 February 2012

Academic Editors: X. Huang and I. Smith

Copyright (C) 2012 Ben Broughton et al. This is an open access article distributed under the Creative Commons Attribution License, which permits unrestricted use, distribution, and reproduction in any medium, provided the original work is properly cited.

\begin{abstract}
Microsurfacing has been utilized in the United States since 1980 as a maintenance treatment for pavement. This paper reviews the benefits, limitations, and factors that contribute to successful applications of microsurfacing. The history of microsurfacing, as well as a definition and process description of the treatment, is included. The body of scientific work on microsurfacing is shown to promote its use in preventative maintenance programs, and the potential for microsurfacing to meet tightening environmental and budgetary restrictions is discussed. Suggestions are given for future research to expand microsurfacing's applications and efficacy stemming from the ability of microsurfacing to be cold-applied and utilize polymers in the bitumen.
\end{abstract}

\section{Introduction}

Microsurfacing is a road maintenance tool that involves laying a mixture of dense-graded aggregate, asphalt emulsion (about $7 \%$ by weight), water, polymer additive (about $3 \%$ by weight), and mineral fillers (about $1 \%$ of weight of total dry mix) to correct or prevent certain deficiencies in pavement conditions [1]. In the same category of pavement treatments as seal coating and thin hot mix asphalt (HMA) overlays, microsurfacing treatments cover the entire width of the roadway to which they are applied [2]. The treatment may be as thin as $3 / 8$ inch $(9.5 \mathrm{~mm})$, or it can fill wheel ruts up to 2 inches $(50.8 \mathrm{~mm})$ deep using multiple passes.

Because of the similar ingredients used in microsurfacing as in slurry seals, microsurfacing is sometimes referred to as a "polymer-modified slurry seal." The difference, however, is slurry seals cure through a thermal process while microsurfacing uses a chemically controlled curing process [3]. Since the use of a polymer-modified binder results in more stability, microsurfacing can be placed in multistone thicknesses, unlike slurry seals. Due to this thickness, more powerful mixers are needed than those required for slurry seals. In order to provide a uniform flow of the mixture into the spreader box, a twin-shafted paddle or spiral auger is needed [4]. Microsurfacing should not be applied if either the pavement or air temperature is below $50^{\circ} \mathrm{F}\left(10^{\circ} \mathrm{C}\right)$ nor if there is a possibility of the treatment freezing within 24 hours of placement [3]. Microsurfacing is generally classified as a preventative maintenance treatment as opposed to a corrective maintenance treatment [5]. Due to this classification by agencies involved in road repair and maintenance, microsurfacing is most often used as a surface treatment to correct rutting, improve surface friction, and extend pavement life by sealing any cracks in the pavement surface [6].

Developed in Germany in the late 1960s and early 1970s, microsurfacing was pioneered as a way to apply a conventional slurry in thick enough layers to fill deep wheel ruts, but in narrow enough courses so that the expensive road striping lines on the autobahns would not be destroyed ("what is microsurfacing," n.d.). Introduced to the United states in 1980 after Dr. Frederick Raschig presented his new slurry system, Ralumac, at the International Slurry Surfacing Association (ISSA) convention, microsurfacing is now used throughout Europe, the US, and Australia and is making inroads into many other areas [4, 7]. The main benefit achieved from microsurfacing over alternative pavement treatments results from the polymer-modified asphalt emulsion that chemically speeds evaporation of moisture. This enables it to set in less than one hour in most instances, requires no rolling, and allows traffic to return to the roadway quickly. 


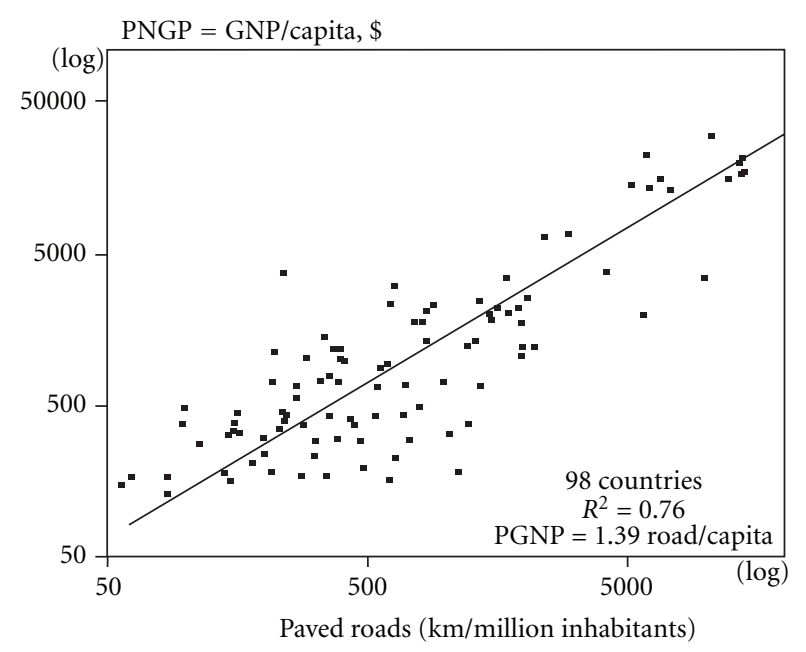

FIGURE 1: Relationship between per capita gross national product (PGNP) and the distance of paved roads (in km) per million inhabitants of 98 countries. PGNP $=1.39 \times$ LPR, where PGNP is per capita GNP ( $\$$ /inhabitant) and LPR is the per capita length (or density) of paved roads ( $\mathrm{km} / 1$ million inhabitants) [8].

\section{Microsurfacing as a Tool for Preventative Maintenance}

A study by Queiroz et al. [8] demonstrated the relationship between a country's economic development and well-being and the quality and quantity of its road infrastructure, as Figure 1 illustrates. For the task of creating and maintaining a country's infrastructure, especially in today's age of tight budgets and ecological sensitivity, it is crucial that existing roads last as long as possible in order to utilize resources as efficiently as possible. Preventative maintenance of existing roadways has been shown to be the most financially efficient use of available resources [9].

Many studies have been done with the goal of developing a set of criteria which will accurately guide decisionmakers in choosing a preventative maintenance strategy that produces the most cost-effective improvements in pavement quality and life [10-18]. Depending on which model or analytical tool is used, answers vary on which treatment is best under a certain set of conditions. The life-cycle cost analysis (LCCA) has been used widely over the last decade by agencies to evaluate road infrastructure projects [10]. Chan et al. [18] report that "the literature is limited in examining the effectiveness of state department of transportation (DOT) life-cycle cost analysis in projecting and picking the pavement alternative with the lowest lifecycle costs." Whether or not effective strategies are in place for choosing the best treatment, the importance of using preventative maintenance treatments is agreed upon as crucial to providing an affordable and usable road system [13, 15]. Among different preventative maintenance treatments, microsurfacing is known to have economical and ecological advantages when used correctly [19].

2.1. Definition. Preventative maintenance (PM) is performed early in a pavement's life cycle and defined as a "program strategy intended to arrest light deterioration, retard progressive failures, and reduce the need for routine maintenance" [15]. PM is differentiated from corrective maintenance which is performed after some deficiency manifests in the pavement [15]. The National Cooperative Highway Research Program (NCHRP) Synthesis 223 indicates that for every dollar spent on preventative maintenance at the correct time in a pavement's life cycle, \$3-4 in future rehabilitation costs could be saved [5]. As shown in Figure 2, these future rehabilitation costs are now $\$ 6-10$ saved for every $\$ 1$ spent on preventative maintenance [20].

An effective PM program should include periodic application of preventive maintenance treatments. In order to be cost-effective, preventive maintenance techniques should regularly be analyzed in order to determine if they are achieving their goal efficiently and economically in light of advancing technology. Microsurfacing to date, when applied by highly trained professionals, can extend pavement life by more than ten years, but often performs poorly when applied using subpa workmanship and practices [21].

2.2. Process. When utilizing microsurfacing as a treatment to existing flexible pavement, the first step is to ensure the pavement is structurally sound and able to be prepared properly to accept the treatment. Proper preparation of the pavement surface includes cleaning and sealing tight cracks, filling wide cracks, and thoroughly brooming and cleaning the pavement to remove loose dirt and contaminants. A tack coat is not normally applied but can be required in specific applications. The application requires a continuousflow mixing unit, a multiblade, double-shafted mixer, and a spreader box.

The microsurfacing is mixed in the continuous-flow mixing unit which accurately mixes the materials and discharges the microsurfacing on a continuous-flow basis. The mixture is spread uniformly by a spreader box with a rear seal as the final strike off and is automatically feathered at the edges. When filling ruts that are deeper than one pass will fill, 24 


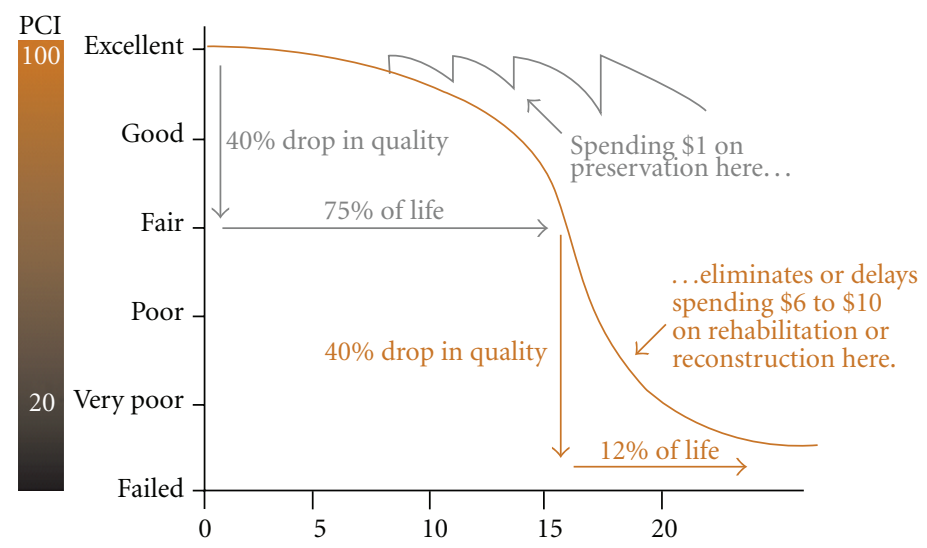

FIGURE 2: Relationship between condition of pavement when treatments are applied and cost of treatment. PCI: pavement condition index; $x$-axis is in years [20].

hours must pass to allow the microsurfacing to cure under traffic before placing additional material [3].

\section{A Review of Microsurfacing}

3.1. Limitations. Factors that reportedly limit the application of microsurfacing consist of established limitations and debated limitations that may act more as suggested guidelines for use. Microsurfacing is shown to be most effective under certain conditions as Labi et al. [22] demonstrated that treatment effectiveness is influenced by climate, traffic loading and highway class, with greater long-term effectiveness generally associated with lower freeze and traffic conditions, and lower pavement class. While this appears to indicate microsurfacing would not be suitable for use on high-traffic roadways, there is a comparable decrease in efficiency of other treatments under heavy traffic loads. Watson and Jared [23] found microsurfacing to perform well for 3-4 years on heavily travelled roads, and Wood and Geib [24] found microsurfacing treatments can be expected to last at least seven years when placed on medium-to-high-volume roads. Additionally, Peshkin et al. [25] stated that microsurfacing is very successful on both low- and high-volume roadways and is recommended for night applications on heavy-traffic streets ([26], n.d.).

In addition to differing reports on traffic load, reports on the effect of pretreated pavement conditions on microsurfacing are also incongruent. The concerns in literature are enough to place this in the limitations section of microsurfacing, although a case can be made on both sides. Hixon and Ooten [27] found that microsurfacing may have a moderate resistance to reflective cracking although it provides no increase in the load-supporting ability of pavement. Temple et al. [28] also reported significantly fewer cracks detected after treatment with microsurfacing. Watson and Jared [23] concluded that microsurfacing may be suitable for use on cracked pavements in lieu of more conventional rehabilitations such as crack sealing, leveling and doublesurface treatments, while Raza [29] also stated that microsurfacing will address cracking. Bae and Stoffels [30] concluded that microsurfacing could be a cost-effective maintenance technique for cracks for one year, and that if more than 3 cracks were detected in the field, microsurfacing would still be a cost-effective maintenance method for any severity crack level. Reflective cracking is the most serious threat to microsurfacing. As other types of cracks may not be structural, much of the debate centers on addressing this type of crack with microsurfacing. Marquis [31] does not claim microsurfacing will stop reflective cracking but does report that microsurfacing slows the progression of reflective cracking. However, other studies are not as optimistic about microsurfacing's ability to positively affect cracking as Kazmierowski and Bradbury [21] declared that it does not inhibit reflective cracking or provide structural support. It is suggested that premature failure of microsurfacing is normally due to placement on unstable, cracked, dirty, or poorly prepared surfaces (resulting in delamination) [32]. Additionally, in a study performed for the Texas Department of Transportation (TxDOT) on six maintenance treatments, microsurfacing was shown to perform the worst at stopping cracks when the base pavement was in poor condition upon application [33]. A reasonable conclusion may be that microsurfacing may at times be used on structurally deficient roads, but it is done so as a stop gap and to limit water intrusion into existing cracks until money is available for more extensive repairs. This fact makes applying microsurfacing treatments at the correct time of the pavement lifecycle paramount, before structural issues develop.

An undisputed limitation of microsurfacing is that it does not level humps in the road. Microsurfacing will fill depressions and ruts but cannot address humps and will, in fact, reproduce a hump in the treatment surface. Any humps should be leveled before applying microsurfacing, and any pothole or crack patches should not be left high [24].

Such limitations are overcome by utilizing timely and appropriate applications of microsurfacing [21]. Untimely applications should be avoided if at all possible as pavement rehabilitation done at the appropriate time often does not require an increase in the pavement's structural strength or thickness, but mainly a restoration or rejuvenation of 
its riding surface. When these limitations are considered, microsurfacing has been proven to be a powerful and versatile tool in pavement preventative maintenance.

3.2. Benefits. Microsurfacing generally receives positive reports in scientific literature. Most studies done on the effectiveness of microsurfacing encourage its use as a preventative maintenance treatment $[6,22,23,27,34-37]$. Per contra, emphasis is placed on the importance of applying microsurfacing at the correct time in a pavement's life cycle to achieve maximum durability and cost-effectiveness before the pavement has deteriorated structurally $[5,15,25,34,38,39]$.

One of the early studies done on microsurfacing in the United States foreshadowed the favorable conclusions of further research by recommending that microsurfacing be approved for routine use in restoring flexible pavements to fill surface ruts and cracks, seal the surface, and restore skid resistance [6]. The Georgia DOT had great success with microsurfacing in correcting smoothness and friction deficiencies, and stopping raveling and load cracking without an increase in pavement noise levels. A good aesthetic value was also achieved with these applications [23].

When a composite index score was calculated based on 11 performance criteria, microsurfacing had the highest score out of thin HMA overlays, slurry seals, and chip seals [40]. Hicks et al. [15] also documented microsurfacing as an appropriate maintenance strategy for more types of pavement distress than any other commonly used strategy, as well as having a longer life expectancy than all but thin HMA overlays which cost $30 \%$ more. HMA overlay is the treatment that most consistently vies with microsurfacing at addressing the broadest range of defects in the most durable manner. The ISSA reports that to address rutted and polished pavement, microsurfacing costs $\$ 17,600$ per lane mile, while milling and HMA cost $\$ 50,000$ per lane mile ([41], n.d.). Also, Labi et al. [22] found that in terms of agency costs, microsurfacing is consistently more cost-effective than thin HMA overlays. It is noteworthy that Marquis [31] concluded overall microsurfacing is performing as well as $9.5 \mathrm{~mm}$ HMA at a lower cost. Labi et al. [22] reported that severe climate has deleterious effects on microsurfacing. This is true of any treatment, however and Reincke et al. [42] reported that microsurfacing will resist deformation, and, because of the polymer content, will also resist movement at high temperatures and cracking at low temperatures. Additionally, Kazmierowski and Bradbury [21] indicated microsurfacing performs well in a wet-freeze environment. Ducasse et al. [43] revealed that enhancing the binder with SBR latex will improve the temperature susceptibility of the binder, although it is not to be applied if freezing is a possibility. Ducasse et al. [43] also pointed out that worker safety is improved due to the cold application.

Reincke et al. [42] and Ducasse et al. [43] both commented on microsurfacing's lower-energy requirement due to ambient temperature applications, lack of harmful emissions associated with HMAs, and conservation of the nonrenewable resources asphalt cement and aggregates because of its thin lift volume. Along these ecological lines, after performing an ecoefficiency analysis, Takamura et al. [19] concluded that microsurfacing "provides a better balance between cost-effectiveness and environmental impact than does a thin hot mix overlay." After microsurfacing in the York region of Canada, Erwin and Tighe [34] found positive safety effects, including crash reduction factors as high as $54 \%$, and suggested more research to be done on the appreciable safety benefits gained from microsurfacing.

Improvements in rutting and friction characteristics are the most frequently mentioned benefits gained from microsurfacing [6, 23, 27, 34, 44]. Hixon and Ooten [27] found a $40 \%$ reduction in the amount of original rutting and substantial increases in the friction characteristics of the pavement. In the aforementioned TxDOT study, microsurfacing was shown to perform most efficiently at reducing bleeding and increasing pavement condition index [33]. Similarly to Freeman et al., Temple et al. [28] found microsurfacing produced a higher PCI and maintained it is longer than chip sealing. Conventional thin asphaltic concrete overlays are expensive and often do not perform well in harsh environments. Also, chip seals, in addition to their performance limitations, are often associated with windshield breakage and increased noise, while microsurfacing does not suffer from either of these limitations to the same degree [21].

Microsurfacing allows for rapid opening of roadways to traffic, often within 1 hour or less of its application under a range of conditions [45]. Reports of a great reduction in ride roughness support microsurfacing's immediate benefits [35], while additional benefits are seen over time as microsurfacing effectively addresses rutting, increases ride quality, and has a significant service life [44]. Labi et al. [44] found that the superiority of microsurfacing in terms of cost is most evident when treatment life is the measure of effectiveness, and least evident when increased pavement condition is used compared to thin HMA overlays. This further strengthens the fact that the benefits seen with microsurfacing are appreciated over time when compared to alternative treatments. Microsurfacing is aesthetically pleasing to people as it restores a black appearance to roadways [23]. Microsurfacing requires no adjustment of curb lines, manholes, guide rails, or bridge clearances due to its thin lift height [42].

Additional benefits from microsurfacing can be seen when indirect cost savings are extracted from the literature. Reincke et al. [42] pointed out that the problem of broken windshields from loose aggregate occurring with other maintenance treatments does not happen with microsurfacing, thereby limiting costly claims after a project. When describing the safety benefits observed on roads that received microsurfacing treatments, Erwin and Tighe [34] also mentioned the financial ramifications of microsurfacing's reduction of automobile crashes, which cost the United States \$164 billion in 2008.

Overall, literature appears to demonstrate that microsurfacing provides the best balance of effectiveness, cost, number of deficiencies for which it addresses, and potential for future development of any preventative maintenance treatment. 
3.3. Factors Contributing to Success. While some limitations of microsurfacing are debated, there is no doubt that an ideal set of conditions for successful application of the treatment exists. In order to limit qualifying every statement with a note about whether agreement is unanimous on the following suggestions, this section should be considered more as a best-practices guide which needs not apply when applying microsurfacing in unusual, debated, or extreme scenarios. In this section, recommendations will be stated as fact, but the reader should understand that there may be researchers that could take exception to certain suggestions in light of the aforementioned debates.

Factors that contribute to the successful use of microsurfacing are well documented. Research suggests that the distribution of the sub-no. 200 (75 micron) fraction is critical to control the reaction rate in microsurfacing emulsions [46]. Due to the fastset of microsurfacing, aggregate characteristics influence quality much more than in conventional slurry seals [15]. Hixon and Ooten [27] reported that applications of microsurfacing in layers of 1.1-1.5" (25.4-38.1 mm) exhibit flushing, rerut, and crack more than lower profile lifts and, therefore, recommend filling deep ruts in two passes.

Critical components to ensure the success of a microsurfacing project include a comprehensive mix design process, quality materials, and the use of a knowledgeable and experienced contractor [21]. Olsen (n.d.) also reported that workmanship is a key factor in the effectiveness of microsurfacing treatments. Other studies have shown that microsurfacing performance is strongly affected by workmanship, and the condition of the pavement at the time of application is the most important factor contributing to success ([15, 35, 47, 48], n.d.). Pederson et al. [6] categorically stated that the quality of a finished microsurfacing project depends greatly on the skill of the operator and crew.

When used as a preventive maintenance treatment on pavements in relatively good condition, microsurfacing may last 7 to 10 years, although longer life times have been claimed [37]. On average, however, the life expectancy of a microsurfacing treatment is 5 to 7 years [49]. When applied in ruts, the life of the treatment is dependent on the stability of the microsurfacing, traffic level, and the condition of the underlying pavement $[22,35]$. The main mechanism of failure is wear in which the surface oxidizes and is abraded over time [50].

Microsurfacing should not be placed on highly deflecting surfaces, cracked surfaces, pavements with base failures, or on dirty or poorly prepared surfaces (resulting in delamination) [32]. As is true of most PM treatments, microsurfacing is much more effective when used on noninterstate and flexible pavements as opposed to interstate and rigid pavements [13].

The body of scientific evidence reveals known limitations and benefits to microsurfacing and certain factors contributing to the success of microsurfacing treatments. There is certainly a need, however, to further identify the techniques contractors have utilized which have led researchers to determine that workmanship is a crucial factor in determining the success of microsurfacing. Such understanding can only be obtained by interviewing contractors who have done the work both successfully and unsuccessfully, then isolating the key variables that create the two outcomes.

3.4. The Future of Microsurfacing. We are currently in a time when both economic and ecologic efficiency are hot-button issues receiving enormous attention in politics, the private sector, and the media. With increasing demands on the world's infrastructure, it is imperative for decision makers to wisely utilize funds $[25,51]$ while also balancing the demands of citizens for environmental sensitivity. Of the preventative maintenance treatments that can effectively and efficiently prolong the service life of roadways, microsurfacing is best poised to meet the increasing demands placed upon such projects.

Much has been written on how to determine when microsurfacing should be applied to pavements in order to limit the application of treatments to pavements too far gone to benefit. The other key factor contributing to the success of microsurfacing is workmanship. Guides have been written $([4,48]$, n.d.) outlining what good workmanship entails, but there are still applications that are applied with poor workmanship. In a meeting on microsurfacing mix design procedures in 2004, ([52], February 25), Glynn Holleran pointed out that the French requires a one-year warranty with their microsurfacing projects, and that instituting that requirement would be in the United States as one means of quality assurance. Would such a requirement address this key aspect of success and be affective in improving the workmanship on microsurfacing projects? Shober et al. [53] conducted a study and found that asphaltic concrete pavement that was warranted by the contractor had an international roughness index (IRI) that was $41 \%$ better, and a pavement distress index (PDI) that was $56 \%$ better, after three years than nonwarranted pavements. This makes a strong case that requiring warranties on all microsurfacing treatments should be common practice in order to improve the workmanship and, therefore, the success of these treatments.

Allan [7] stated that one of the greatest challenges for our industry is to be able to meet the ever-changing environmental regulations. Cold-applied-non-polluting maintenance products for road systems will definitely be used. The ISSA reports that microsurfacing emits $1 / 4$ the potential of HMA and $1 / 3$ the potential of modified HMA with regards to kilograms of ethene, carbon dioxide, and kilograms of nitrogen dioxide when measured per lane mile ([41], n.d.). Sinha and Labi [54] similarly stated the impact of environmentally friendly PM treatments by pointing out the monetary costs of air pollution and the global agreements on air quality standards and air-quality legislation. Takamura et al. [19] concluded that a small improvement in durability of the microsurfacing would result in significant cost and ecological advantages, and that future improvements in microsurfacing technologies could lead to additional cost and environmental advantages. Along the same lines with regards to microsurfacing, Allan [7] predicts that the possibilities for the inclusion of performance-enhancing additives above and beyond those already available will greatly impact the equipment used in the future. One such study by 
Holleran and Reed [55] looked at improving the crack resistance of microsurfacing by increasing polymer content, as well as adding fibers to the binders. They found that while fibers do not help, certain polymers do increase flexibility and cracking resistance of microsurfacing, especially in association with asphalt rubber crumb. More studies need to be done on ways to make microsurfacing less susceptible to reflective cracking, effectively addressing one of the two factors that contribute most to failure of this treatment.

\section{Conclusion}

This paper was a comprehensive study of the microsurfacing with a thorough review of literature on the topic. Microsurfacing is still an important player in the preventative maintenance of the nation's roadways. Even more importantly, microsurfacing is poised above all other treatments to meet the challenges of increasingly strict environmental regulations and budgetary restrictions the paving industry faces in the coming years. While microsurfacing does have limitations, the potential to develop additives to minimize or overcome these limitations is great. With regard to environmental impact, microsurfacing is also a nonpolluting, cold-applied, zero-emissions treatment that is well ahead of treatments with similar durability.

This paper recommends research be done to identify additives that will enhance the already considerable usefulness and durability of microsurfacing in order to increase its cost-effectiveness. Additionally, research is needed to improve the "greenness" of microsurfacing through the use of unique and sustainable ingredients. This research should begin now so the treatments will be ready when the upcoming regulations require changes to the current PM practices.

\section{References}

[1] D. Hein, C. Olidis, M. Darter, and H. Von Quintus, "Impact of recent technology advancements on pavement life," in Proceedings of the Annual Conference of the Transportation Association of Canada, St. John's, 2003.

[2] S. Labi, K. S. Hwee, G. Lamptey, and C. Nunoo, "Longterm benefits of microsurfacing applications in Indianamethodology and case study," in Proceedings of the 85th Annual Meeting of the Transportation Research Board, Washington, DC, USA, 2006.

[3] R. Campbell, "Asphalt in pavement maintenance," in The Asphalt Handbook, B. Boyer, Ed., pp. 569-616, Asphalt Institute, College Park, Md, US, 2007.

[4] International Slurry Surfacing Association (ISSA), Recommended Performance Guidelines for Micro-Surfacing, Annapolis, Md, USA, 2010.

[5] D. N. Geoffroy, Cost-effective Preventative Maintenance. National Cooperative Highway Research Program Synthesis of Highway Practice 223, Transportation Research Board, National Research Council, Washington, DC, USA, 1996.

[6] C. M. Pederson, W. J. Schuller, and C. D. Hixon, "Microsurfacing with natural latex-modified asphalt emulsion: a field evaluation," Transportation Research Record, no. 1171, pp. 108-112, 1988.
[7] G. Allan, "History of slurry and the international slurry surfacing association," in Proceedings of the International Slurry Surfacing Association's 5th World Congress, Berlin, Germany, March 2002.

[8] C. Queiroz, R. Haas, and Y. Cai, "National economic development and prosperity related to paved road infrastructure," Transportation Research Record, vol. 1455, pp. 147-152, 1994.

[9] I. M. Syed, T. J. Freeman, R. E. Smith et al., "Effectiveness of highway maintenance treatments used in Texas," in Proceedings of the Symposium on Flexible Pavement Rehabilitation and Maintenance, pp. 136-150, ASTM STP 1349, 1999.

[10] Z. Li and S. Madanu, "Highway project level life-cycle benefit/cost analysis under certainty, risk, and uncertainty: methodology with case study," Journal of Transportation Engineering, vol. 135, no. 8, pp. 516-526, 2009.

[11] C. Y. Chu and P. Durango-Cohen, "Incorporating maintenance effectiveness in the estimation of dynamic infrastructure performance models," Computer-Aided Civil and Infrastructure Engineering, vol. 23, no. 3, pp. 174-188, 2008.

[12] S. Labi and K. Sinha, "Measures of short-term effectiveness of highway pavement maintenance," Journal of Transportation Engineering, vol. 129, no. 6, pp. 673-683, 2003.

[13] S. Labi and K. Sinha, "Life-cycle evaluation of flexible pavement preventive maintenance," Journal of Transportation Engineering, vol. 131, no. 10, pp. 744-751, 2005.

[14] R. Pasupathy, S. Labi, and K. Sinha, "Optimal reconstruction periods for stochastically deteriorating infrastructures," Computer-Aided Civil and Infrastructure Engineering, vol. 22, no. 6, pp. 389-399, 2007.

[15] R. G. Hicks, K. Dunn, and J. Moulthrop, "Framework for selecting effective preventive maintenance treatments for flexible pavements," Transportation Research Record, no. 1597, pp. 1-10, 1997.

[16] A. Chassiakos, C. Panagolia, and D. Theodorakopoulos, "Development of decision-support system for managing highway safety," Journal of Transportation Engineering, vol. 131, no. 5, pp. 364-373, 2005.

[17] S. Hesp, A. Soleimani, S. Subramani et al., "Asphalt pavement cracking: analysis of extraordinary life cycle variability in eastern and northeastern Ontario," International Journal of Pavement Engineering, vol. 10, no. 3, pp. 209-227, 2009.

[18] A. Chan, G. Keoleian, and E. Gabler, "Evaluation of lifecycle cost analysis practices used by the Michigan department of transportation," Journal of Transportation Engineering, vol. 134, no. 6, pp. 236-245, 2008.

[19] K. Takamura, K. P. Loka, and R. Wittlinger, "Microsurfacing for preventive maintenance: eco-efficient strategy," in Proceedings of the International Slurry Seal Association Annual Meeting, Maui, Hawaii, USA, 2001.

[20] L. Galehouse, J. S. Moulthrop, and R. G. Hicks, "Principles of pavement preservation: definitions, benefits, issues, and barriers," TR News, pp. 4-15, 2003.

[21] T. J. Kazmierowski and A. Bradbury, "Microsurfacing: solution for deteriorated freeway surfaces," Transportation Research Record, no. 1473, pp. 120-130, 1995.

[22] S. Labi, M. I. Mahmodi, C. Fang, and C. Nunoo, "Costeffectiveness of microsurfacing and thin hot-mix asphalt overlays: comparative analysis," in Proceedings of the 86th Annual Meeting of the Transporation Reseach Board, Washington, DC, USA, 2007.

[23] D. Watson and D. Jared, "Georgia department of Transportation's experience with microsurfacing," Transportation Research Record, no. 1616, pp. 42-46, 1998. 
[24] T. J. Wood and G. J. Geib, "State wide microsurfacing project," Tech. Rep. MN/RC-2001-11, Office of Materials and Road Research, Minnesota Department of Transportation, Saint Paul, Minn, USA, 1999.

[25] D. G. Peshkin, T. E. Hoerner, K. A. Zimmerman et al., "Optimal timing of pavement maintenance treatment applications," NCHRP Report 523, Transportation Research Board, Washington, DC, USA, 2004.

[26] International Slurry Surfacing Association (ISSAa), "Microsurfacing: pavement resurfacing," Annapolis, Md, USA, http:// www.pavementpreservation.org/toolbox/guidelines.html.

[27] C. D. Hixon and D. A. Ooten, "Nine years of microsurfacing in Oklahoma," Transportation Research Record, no. 1392, pp. 13-19, 1993.

[28] W. Temple, S. Shah, H. Paul, and C. Abadie, "Performance of Louisiana's chip seal and microsurfacing program, 2002," Transportation Research Record, no. 1795, pp. 3-16, 2002.

[29] H. Raza, "State of the practice: design, construction, and performance of microsurfacing," Tech. Rep. FHWA-SA-94-051, Federal Highway Administration, DOT, Washington, DC, USA, 1994.

[30] A. Bae and M. Stoffels, "Economic effects of microsurfacing on thermally-cracked pavements," KSCE Journal of Civil Engineering, vol. 12, no. 3, pp. 177-185, 2007.

[31] B. Marquis, "The use of micro-surfacing for pavement preservation," Tech. Rep. 02-3, Transportation Research Division, Maine Department of Transportation, 2004.

[32] H. Anderson, "Slurry seal vs. microsurfacing," in Proceedings of the 34th Annual Utah Asphalt Conference, South Towne Exposition Center, Sandy, Utah, USA, April 2009, http://www. pavementpreservation.org/toolbox/guidelines.html.

[33] T. Freeman, D. Pinchett, R. Haobo, and C. Spiegelman, Analysis and Treatment Recommendations from the Supplemental Maintenance Effectiveness Research Program (SMERP), Texas Transportation Institute, College Station, Tex, USA, 2002.

[34] T. Erwin and S. L. Tighe, "Safety effect of preventive maintenance: a case study of microsurfacing," Transportation Research Record, no. 2044, pp. 79-85, 2008.

[35] J. S. Moulthrop, L. Day, and W. R. Ballou, "Initial improvement in ride quality of jointed, plain concrete pavement with microsurfacing: case study," Transportation Research Record, no. 1545, pp. 3-10, 1996.

[36] T. J. Kazmierowski, A. Bradbury, J. Hajek, and G. Jones, "Effectiveness of high-performance thin surfacings in a wetfreeze environment," Transportation Research Record, no. 1392, pp. 3-12, 1993.

[37] J. Van Kirk, "Long lasting slurry pavements," in Proceedings of the International Slurry Seal Association Conference, Amelia Island, Fla, USA, 2000.

[38] D. H. Chen, D. F. Lin, and H. L. Luo, "Effectiveness of preventative maintenance treatments using fourteen SPS-3 sites in texas," Journal of Performance of Constructed Facilities, vol. 17, no. 3, pp. 136-143, 2003.

[39] A. S. Rajagopal and K. P. George, "Pavement maintenance effectiveness," Transportation Research Record, vol. 1276, pp. 62-68, 1990.

[40] R. G. Hicks, S. B. Seeds, and D. G. Peshkin, Selecting a Preventative Maintenance Treatment for Flexible Pavements, Foundation for Pavement Preservation, Washington, DC, USA, 2000.

[41] International Slurry Surfacing Association (ISSAb), "High performance slurry systems," Annapolis, Md, USA, http:// www.pavementpreservation.org/toolbox/guidelines.html.
[42] G. Reincke, W. R. Ballou, S. L. Engber, and T. M. O'Connell, "Studies of polymer modified microsurfacing materials in highway maintenance," in Proceedings of the ISSA, pp. 45-83, International Slurry Surfacing Association, February 1989.

[43] K. Ducasse, T. Distin, and L. Osborne, "The use of microsurfacing as a cost effective remedial action for surface rutting," in Proceedings of the 8th Conference on Asphalt Pavements for Southern Africa, Sun City, South Africa, September 2004.

[44] S. Labi, G. Lamptey, and S. H. Kong, "Effectiveness of microsurfacing treatments," Journal of Transportation Engineering, vol. 133, no. 5, pp. 298-307, 2007.

[45] G. Holleran, ABC's of Slurry Surfacing, Asphalt Contractor Magazine, 2001.

[46] P. Schilling, "Success with bituminous emulsions requires a well balanced chemistry of emulsions, bitumen and aggregate," in Proceedings of the International Slurry Surfacing Association Conference, Berlin, Germany, 2002.

[47] R. E. Smith and C. K. Beatty, "Microsurfacing usage guidelines," Transportation Research Record, no. 1680, pp. 13-17, 1999.

[48] International Slurry Surfacing Association (ISSAc), "Microsurfacing: quality control," Annapolis, Md, USA, http://www. pavementpreservation.org/toolbox/guidelines.html.

[49] S. Shatnawi, Ed., Maintenance Technical Advisory Guide Volume I Flexible Pavement Preservation, Caltrans Division of Maintenance, Sacramento, Calif, USA, 2nd edition, 2008.

[50] P. Kumar and A. Gupta, "Case Studies on Failure of Bituminous Pavements," in Proceedings of the 1st International Conference on Pavement Preservation, pp. 505-518, University of California, Berkeley Institute of Transportation Studies, Technology Transfer Program, Berkeley, Calif, USA, 2010.

[51] A. I. Al-Mansour, K. C. Sinha, and T. Kuczek, "Effects of routine maintenance on flexible pavement condition," Journal of Transportation Engineering, vol. 120, no. 1, pp. 65-73, 1994.

[52] Federal Highway Administration (FHWA) and National Center for Pavement Preservation (NCPP), "Slurry/Micro-Surface Mix Design Procedure," Minutes from Phase 1 Meeting, San Diego, Calif, USA, 2004, http://www.google.com/url?sa=t\& $\mathrm{rct}=\mathrm{j} \& \mathrm{q}=\& \mathrm{esrc}=\mathrm{s} \& \mathrm{frm}=1 \&$ source $=$ web $\& \mathrm{~cd}=3 \& \mathrm{ved}=0 \mathrm{CDgQ}$ FjAC\&url=http\%3A\%2F\%2Fwww.dot.ca.gov\%2Fnewtech\%2 Fmaintenance $\% 2$ Fslurry_micro-surface $\% 2$ Fmembers-only $\%$ 2Fdocs\%2FMinutes_SD_2-25-04-r3.doc\&ei=HhyQT63fIIGC 2AXDntzsBA\&usg=AFQjCNG1nU0Gcf4GCK_4x4UCD3ZaL IjU3g.

[53] S. F. Shober, G. C. Whited, and K. W. McMullen, "Wisconsin department of transportation's asphaltic pavement warranties," Transportation Research Record, no. 1543, pp. 113119, 1996.

[54] K. Sinha and S. Labi, Transportation Decision Making: Principles of Project Evaluation and Programming, John Wiley \& Sons, Hoboken, NJ, USA, 2007.

[55] G. Holleran and J. R. Reed, Super Microsurfacings, "World of Asphalt” AAPA, Sydney, Australia, 2000. 

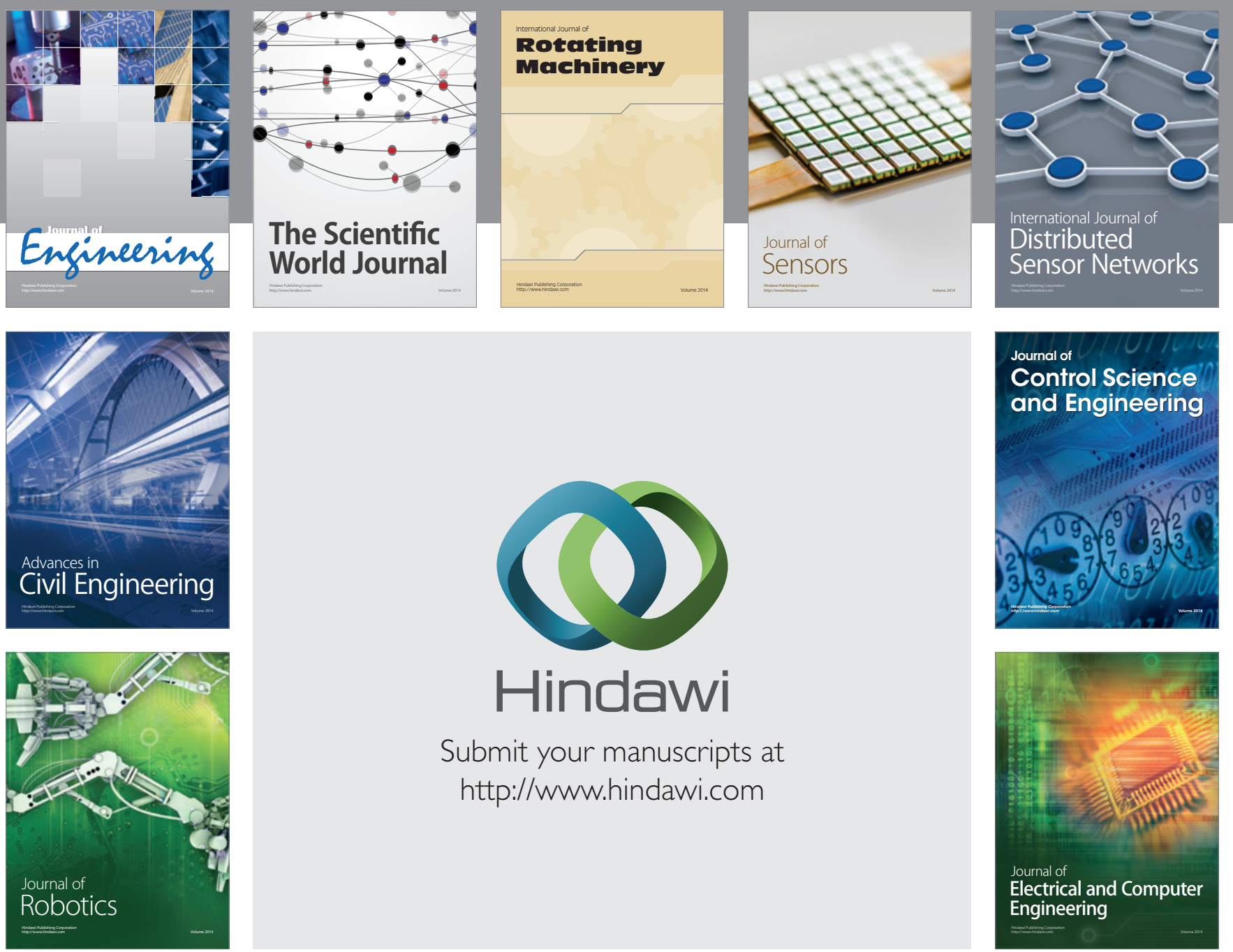

Submit your manuscripts at

http://www.hindawi.com
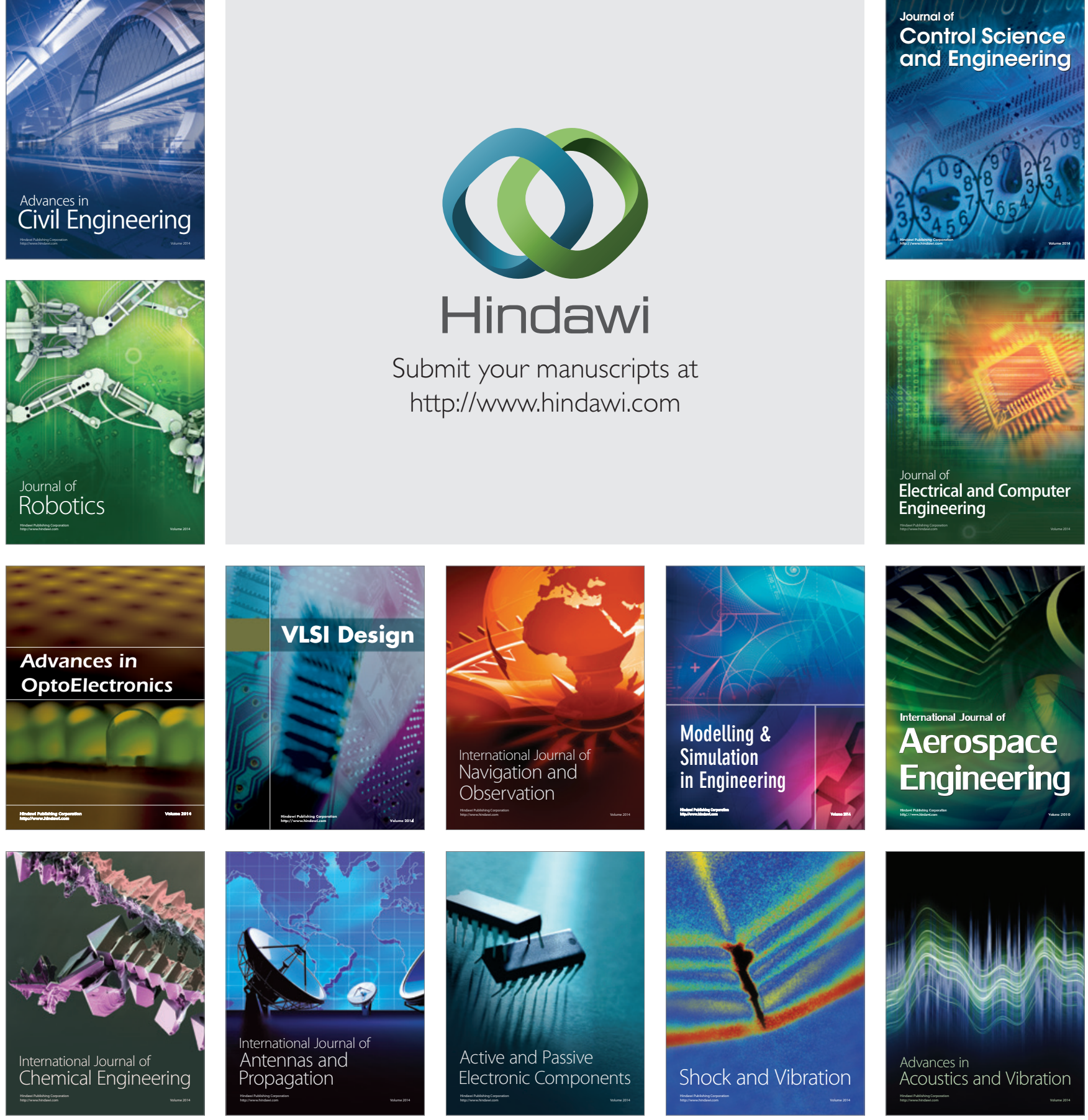